ISSN: 1979-7362

\title{
Mempelajari Tingkat Kerusakan Gabah yang di Panen Dengan Menggunakan Combine Harvester Tipe Kubota DC 70
}

\author{
Fachry Muhammad ${ }^{1}$, Mursalim ${ }^{1}$ dan Suhardi ${ }^{1}$ \\ 1)Program Studi Teknik Pertanian, Universitas Hasanuddin Makassar
}

\begin{abstract}
ABSTRAK
Pemanenan merupakan salah satu proses utama dalam budidaya, Pemanenan padi bertujuan untuk mendapatkan gabah dari lapangan pada tingkat kematangan optimal, mencegah kerusakan dan kehilangan hasil seminimal mungkin. Salah satu teknologi pemanenan yang sering digunakan sekarang ini yaitu comabine harvester, yaitu alat pemanen padi yang dapat memotong bulir tanaman yang berdiri, merontokkan dan membersihkan gabah sambil berjalan dilapangan. Namun dalam penggunaanya juga terjadi kerusakaan pada padi. Untuk mengetahui tingkat kerusakan pada penggunaan comabine harvester digunakan metode sampling pada hasil panen. Dengan cara mengambil $1 \mathrm{~kg}$ dari setiap karung setelah itu dari $1 \mathrm{~kg}$ diambil lagi 100 gram. Kemudian memilih gabah yang rusak, patah, yang masih ada malainya, dan yang masih ada kotorannya. Dari hasil penelitian didapatkan persentase gabah utuh, gabah patah, gabah rusak, gabah yang memiliki malai masing-masing sebesar $95 \%$, $0,07 \%, 0,713 \%, 3,735 \%$ sementara untuk kotoran yang ikut bersama gabah sebesar $0,414 \%$. Dari hasil tersebut dapat disimpulkan bahwa comabine harvester memeliki kinerja yang bagus dalam pemanenan dengan persentase gabah utuh yang besar.
\end{abstract}

\section{Kata kunci: Pemanenan, Combine Harvester, Gabah, Kerusakan Panen}

\section{PENDAHULUAN}

\section{Latar Belakang}

Proses pemanenan merupakan salah satu proses utama dalam budidaya, panen merupakan pekerjaan akhir dari budidaya tanaman (bercocok tanaman), tapi merupakan awal dari pekerjaan pascapanen, yaitu melakukan persiapan untuk penyimpanan dan pemasaran. Pemanenan padi bertujuan untuk mendapatkan gabah dari lapangan pada tingkat kematangan optimal, mencegah kerusakan dan kehilangan hasil seminimal mungkin. Pemanenan padi tidak akan menguntungkan dan memusakan jika prosesnya dilakukan dengan cara yang kurang benar dan pada umur panen yang tidak tepat

Diharapkan penggunaan mesin panen padi yang canggih tersebut akan mendukung keberhasilan panen. Dengan menggunakan combine harvester sebagai alat pemanen tidak selamanya hasil panen yang dihasilkan itu bagus karena menggunakan alat tersebut ada juga padi yang dihasilkan mengalami kerusakan, kehilangan, dan padi yang masi ada malainya. Hal itu disebabkan karena suhu dan tingkat kematangan pada padi belum cukup serta kurangnya keahliaan supir pada saat pemanenan.

Combine harvester adalah alat pemanen padi yang dapat memotong bulir tanaman yang berdiri, merontokkan dan membersihkan gabah sambil berjalan dilapangan. Dengan demikian waktu pemanen lebih singkat dibandingkan dengan menggunakan tenaga manusia (manual) serta tidak membutuhkan jumlah tenaga kerja manusia yang besar seperti pada pemanenan tradisional. Penggunaan alat ini memerlukan investasi yang besar dan tenaga terlatih yang dapat mengoprasikan alat ini.Dari penjabaran diatas, maka dianggap perlu dilakukan penilitian ini untuk mengetahui angka kerusakan yang disebabkan oleh penggunaan combine harvester . 


\section{Tujuan dan Kegunaan}

Tujuan dari penelitian ini agar mengetahui jumlah kerusakan padi yang dipanen menggunakan combine harvester

Sedangkan kegunaan penilitian ini agar memberikan informasi tentang angka kerusakan beras akibat menggunakan combine harvester

\section{Rumusan Masalah}

Rumusan masalah pada penelitian ini yaitu belum diketahui berapa jumlah gabah yang rusak, patah, bermalai, dan kotoran gabah yang dipanen dengan menggunakan mesin combine harvester.

\section{METODE PENELITIAN}

\section{Waktu dan Tempat}

Penelitian ini akan dilaksanakan pada bulan Agustus - september 2016 Di Wilayah desa Alatengngae, kabupaten Maros, kecamatan Bantimurung.

\section{Alat dan Bahan}

Alat yang digunakan pada penelitian ini yaitu, pulpen, kertas label, kantong plastik, tachometer, stopwatch, alat meteran dan timbangan digital.

Bahan yang digunakan pada penelitian ini yaitu, gabah.

\section{Metode Penelitian}

Pada penelitian ini, dilakukan pada 1 lahan persawahan siap panen sebagai tempat pengoperasian combine harvester, untuk mengetahui tingkat kerusakan gabah yang dipanen menggunakan combine harvester dilakukan perhitungan gabah yang rusak, gabah yang masih ada kotorannya,gabah yang masih ada malainya dan gabah yang patah dan dilakukan pengambilan data dilapangan.

\section{Prosedur Penelitian}

\section{a. Pengambilan Data Dilapangan}

1. Menetapan luas areal persawahan

2. Menetapkan laju lintasan mesin combine harvester
3. Menetapkan kecepatan maju mesin combine harvester $25 \mathrm{~km} / \mathrm{jam}$ (spedometer)

4. Mengukur waktu pengambilan hasil panen

5. Mengambil sampel hasil panen

6. Menghitung total gabah hasil panen

7. Mengukur tingkat kerusakan gabah

b. Menghitung gabah yang rusak, gabah yang masih ada kotorannya, gabah yang masih ada malainya dan gabah yang patah

1. Menyiapkan hasil panen gabah dari karung

2. Mengambil $1 \mathrm{~kg}$ dari setiap karung setelah itu dari $1 \mathrm{~kg}$ ambil 100gram gabah tersebut

3. Menyiapkan wadah

4. Memasang label disetiap gabah yang sudah dipisahkan

5. Memilih gabah yang rusak, patah, yang masih ada malainya, dan yang masih ada kotorannya

6. Mencatat hasil perhitungan manual tersebut.

\section{Bagan Alir}

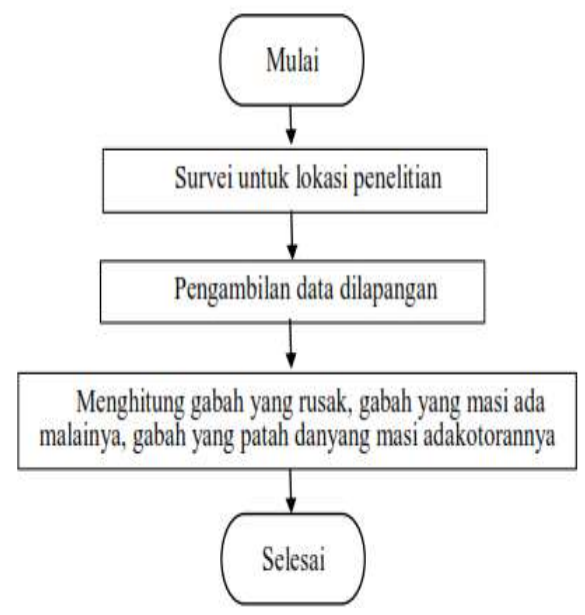




\section{HASIL DAN PEMBAHASAN}

\section{Kondisi Geografik Area Penelitian}

Penelitian inidilaksanakan di areal persawahan yang terletakdi Desa Alatangngae, Kecamatan Bantimmurung, Kabupaten Maros, letak geografis pada area penelitian yaitu terletak di bagian barat Sulawesi Selatan antara 40 45'$50^{\circ} 07^{\prime}$ Lintang Selatan dan 1090205'$129^{\circ} 12^{\prime}$ Bujur Timur yang berbatasan dengan Kabupaten Pangkep sebelah Utara, Kota Makassar dan Kabupaten Gowa disebelah Selatan, Kabupaten Bone disebelah Timur dan Selat Makassar disebelah Barat.

Desa alat enggae merupakan salah satu penghasil beraster besar di Sulawesi selatan. Penelitian ini dilaksanakan di salah satu petakan sawah di areal persawahan tersebut, tepatnya pada petakan bernomor 134. Luas petakan yang dipanenseluas $741,554 \mathrm{~m}^{2}$, kondisi petakan ketikaproses pemanenan berlangsung yaitulah andalam keadaan kering, serta padi yang akan dipanen dalam keadaan matang dan siap panen. Pemanenan berlangsung pada siang hari pukul 14.00 wita. Proses pemanenan berlangsung cepat yaitu 18 menit. Cepat lambatnya proses pemanenan tergantung dari operator mesin.

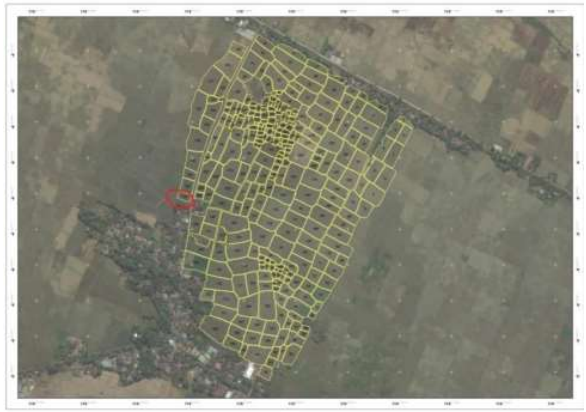

Gambar 1. Peta lokasi penelitian.

Dari proses pemanenan didapatkan hasil panen sebanyak 19 karung, dimana setiap karung berisi $50 \mathrm{~kg}$. Selama proses pemanenan cuaca serta kondisi dilapangan sangat membantu dalam proses tersebut.

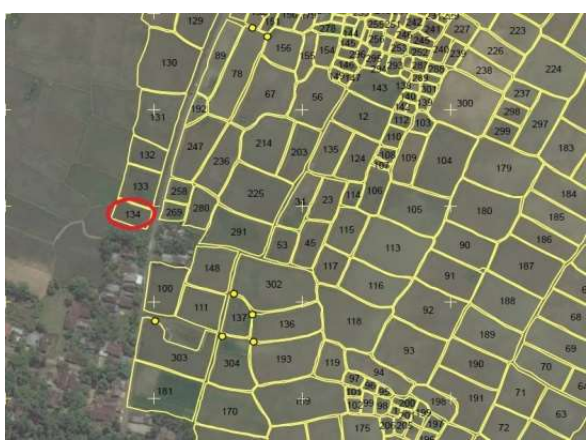

Gambar 2. Peta lokasi penelitian.

Pada petakan bernomor 134 terletak dipinggir jalan dan kondisi lahan pada saat pemanenan kering dan cuaca pada hari itu cerah. Areal persawahan dibantimurung mencapai 25 ribu hektar dan menjadi areal persawahan terluas di kabupaten Maros. Didesa alattengae tersebut mencapai hasil panen antara 6,00 sampai 9,00 ton per hektar. Kondisi lahan pada petak 134 ketika proses pemanenan berlangsung tanahnya kering, kondisi padi yang akan dipanen sudah pada kondisi dimana padi tersebut sudah layak dipanen. Pengalaman sopir pada saat menjalankan atau mengoprasikan alat pada saat pemanenan cukup terampil dan berpengalaman, pengalaman sopir sudah hampir 6 tahun mengoprasikan mesin combine harvester, dalam melakukan pemanenan dalam satu petak operator mengoprasikan mesin tersebut kira-kira 15-20 menit dan kendala dalam melakukan pemanenan menggunakan combine harvester yaitu kinerja alat sangat dipengaruhi oleh kondisi lahan pada saat pemanenan. Jika padasaat panen lahan dalam kondisi lahan tergenang air sangat, maka pergerakanalat terhambatdan kecepatan alat berkurang.

\section{Tingkat Kerusakan Gabah}

\section{Kondisi Kerusakan Gabah}

Tingkat kerusakan gabah yang diamati pada penelitian ini yaitu gabah yang utuh, gabah rusak, gabah patah, gabah yang masih terdapat malai, dan tingkat kotoran gabah. Kelima kondisi kerusakan gabah tersebut dapat dilihat pada Gambar 3. 


\section{Tingkat Kerusakan Gabah}

Dari penelitian didapatkan nilai tingkat kerusakan gabah untuk masingmasing parameter yang dapat diamati. Besar tingkat kerusakan gabah utuh masing-masing paramter dapat dilihat pada pada Tabel 1:

Tabel 1. Nilai Tingkat Kerusakan Gabah

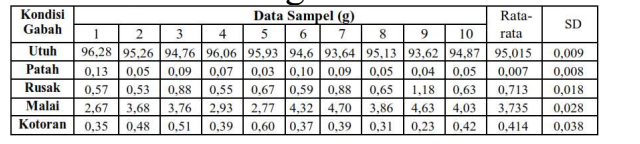

Pada Tabel 1 dapat dilihat 5 tingkat kerusakan gabah yang dihitung berdasarkan data yang dikumpulkan dilapangan. Berdasarkan tabel 1 dapat dilihat bahwa kondisi gabah yang diamati yaitu utuh, patah, rusak, malai, dan kotoran. Untuk kondisi gabah yang utuh dari 10 sampel yang dihitung didapatkan rata-rata yaitu sebesar 95,015 g. Kondisi gabah patah dari 10 sampel didapatkan rata-rata kondisi gabah yang patah sebesar $0,07 \mathrm{~g}$, Untuk kondisi gabah yang rusak didapatkan rata-rata sebesar $0,713 \mathrm{~g}$, sedangkan untuk gabah yang masih memiliki malai dari hasil perhitungan didapatkan rata-rata untuk kondisi yang masih memiiki malai yaitu sebesar $3,735 \mathrm{~g}$, dan yang terakhir untuk kondisi gabah yang masih terdapat kotoran dari 10 sampel didapatkan rata-rata sebesar 0,414 g.

Berdasarkan Tabel 1 dapat dilihat bahwa kondisi gabah dengan rata-rata kerusakan tertinggi terdapat pada kondisi gabah yang masih memiliki malai yaitu sebesar 3,735 g, sedangkan kondisi gabah dengan rata-rata kerusakan terendah terdapat pada kondisi gabah yang patah sebesar 0,07 g. Tetapi tingkat kerusakan gabah dari hasil panen menggunakan combine harvester sangat rendah jika dibandingkan dengan gabah utuh hasil panen yang didapat dari proses panen menggunakan mesin yang sama, gabah utuh yang didapatkan dari pemanenan sebesar 95,015 g.

\section{Persentase Tingkat Kerusakan Gabah}

Pada penelitian ini didapatkan nilai persentase tingkat kerusakan gabah yang dipanen dengan menggunakan menggunakan alat combine harvester dan pada perhitungan gabah secara manual didapatkanlah hasil persentase yang dapat diamati pada tabel berikut:

Tabel 2. Persentase kondisi gabah

\begin{tabular}{|c|c|}
\hline $\begin{array}{c}\text { Kondisi } \\
\text { Gabah }\end{array}$ & Presentase (\%) \\
\hline Utuh & 95,015 \\
\hline Patah & 0,07 \\
\hline Rusak & 0,713 \\
\hline Malai & 3,735 \\
\hline Kotoran & 0,414 \\
\hline Jumlah & $\mathbf{1 0 0}$ \\
\hline
\end{tabular}

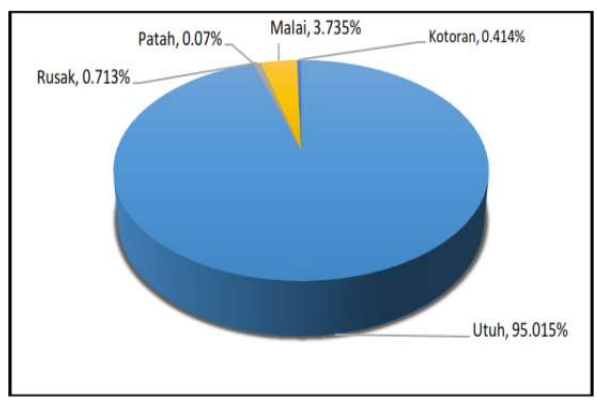

Gambar 3. Diagram kondisi gabah.

Gambar 3 merupakan diagram yang menunjukkan persentase kondisi gabah dari kondisi gabah yang masih utuh, rusak, patah, masih memiliki malai serta kotoran dari hasil pemanenan dengan menggunakan combine harvester Kubota DC 70. Dari diagram diatas (Gambar 3) diketahui bahwa persentase tertinggi terdapat pada kondsis gabah utuh yaitu $95 \%$, artinya $95 \%$ gabah hasil panen menggunakan combine harverster tipe Kubota DC 70 tidak mengalami kerusakan baik berupa patah maupun retak, hal ini didasarkan pada pengujian gabah berdasarkan sampel yang telah diambil diareal persawahan yang menjadi objek penelitian. Sedangkan untuk persentase kondisi gabah yang patah yaitu sebesar $0,07 \%$ dari jumlah sampel gabah yang diambil diareal persawahan tersebut. 
Untuk gabah dengan kondisi rusak juga memiliki persentase yang sangat kecil yaitu sebesar $0,713 \%$. Presentase kondisi gabah yang masih memiliki malai juga terbilang kecil yaitu hanya sebesar 3,735\% sedangakan untuk kotoran yang ikut bersama gabah dari proses pemanenan yaitu sebesar $0,414 \%$. Dari data diatas dapat dilihat bahwa kondisi gabah hasil panen menggunakan combine harvester dengan tipe Kubota DC 70 terbilang cukup bagus karena dari 10 sampel yang diuji kondisi gabah dengan persentase terbanyak yaitu kondisi gabah yang masih utuh sebesar $95 \%$.

\section{PENUTUP}

\section{Kesimpulan}

Setelah melalui proses perhitungan untuk mendapatkan persentase tingkat kerusakan gabah dapat disimpulkan bahwa:

1. Kinerja combine harvester sangat bagus pada parameter keutuhan gabah dengan nilai persentase gabah utuh lebih besar dibandingkan tingkat kerusakan gabah.

2. Kinerja combine harvester tergantung pada kondisi operator, kondisi lahan, serta kondisi tanaman padi pada proses pemanenan berjalan lancar.

\section{DAFTAR PUSTAKA}

Anonim, 2015. Meningkatkan Produktifitas Padiyang Efisien dalam Peggunaan

Air.http://repository.usu.ac.id/bitstrea $\mathrm{m} / 123456789 / 22086 / 5 /$ Chapter\%20I. pdf. Diakses Tanggal 25 April 2016

Ananto E. E., A. Setyono dan Sutrisno, 2003. Panduan teknis penangnan panen dan pascapanen padi dalam sistem usaha tani tanaman ternak. Puslitbangtan, Bogor.

Fagi, 2001. Peranan Padi Indonesia Sebagai Sumber Daya Genetik Padi Modern. Raja Badan Litbang Unisri. Jakarta.
Harjadi, S. 1993. Budidaya Tanaman Pangan Padi Hibrida. Gramedia Pustaka Utama. Jakarta.

Irwanto, K, 1980. Alat dan Mesin Budidaya Pertanian. Departemen Mekanisasi Pertanian, Fakultas Mekanisasi dan Teknologi Pertanian Hasil Pertanian. Institut Pertanian Bogor. Bogor

Setyono, A, 2000. Pengujian Pemanenan Padi Sistem Kelompok Dengan Memanfaatkan Kelompok Jasa Pemanen dan Jasa Perontok.Disamping Pada Apresiasi Seminar Hasil Penelitian Balipta.

Siregar, Hadrian, 1981. Budidaya Tanaman Padi di Indonesia dan Klasifikasi Gabah. Sastra Hudaya. Bogor.

Smith, H, P., 1965. Farm Macheneri and equiepment. Tata Mcgraw Hill Publishing Company LTD. New Delhi.

Sulistiadji, K, 2006. Buku Reaper. Teknologi Mekanisasi Mesin Pertanian Padi.

Suparyono, S, 2009. Padi Hibrida Mendukung Swasembada Laju Pertumbuhan vs Laju Peningkatan Produksi Kebutuhan Pangan. Diakses dhttp://www.google.com/localhost/ag romedia/?pilih=news\&aksi=lihat. Diakses Pada Tanggal 1 April 2016 pukul 09.15 WITA. Makassar.

Sutiyono, 2012. Alat dan Mesin Pengolahan Tanah dan Padi Secara Tradisional. Bogor.

Suwarno, 2001. Kemajuan Penelitian dan Produktifitas Benih Padi Hibrida Di Indonesia. Makalah Penelitian Teknologi Benih Padi Hibrida, Yogyakarta

Vergara, SB, 1990. Bercocok Tanam Padi Hibrida. Bappennas. Jakarta. 